\title{
Preoperative stress conditioning prevents paralysis after experimental aortic surgery: Increased heat shock protein content is associated with ischemic tolerance of the spinal cord
}

George A. Perdrizet, MD, PhD, FACS

Christopher J. Lena, MD

David S. Shapiro, BS

Michael J. Rewinski, MS

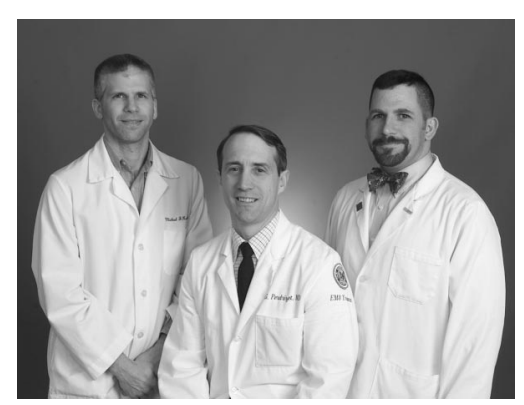

Rewinski, Perdrizet, Shapiro (left to right)
From the Departments of Surgery, Trauma and Research, Hartford Hospital and University of Connecticut School of Medicine, Farmington, Conn.

Funding was provided by Hartford Hospital Research Committee.

Received for publication March 2, 2000; revisions requested June 26, 2000; revisions received Oct 8, 2001; accepted for publication Dec 4, 2001.

Address for reprints: George A. Perdrizet, $\mathrm{MD}, \mathrm{PhD}, \mathrm{FACS}$, Director of Research, Department of Surgery and Trauma, Hartford Hospital, 80 Seymour St, Hartford, CT 06102-5037 (E-mail: gperdri@ harthosp. org).

J Thorac Cardiovasc Surg 2002;124:162-70

Copyright ( $(2) 2002$ by The American Association for Thoracic Surgery

0022-5223/2002 \$35.00+0 $\quad \mathbf{1 2 / 1 / 1 2 2 3 1 2}$

doi: $10.1067 / \mathrm{mtc} .2002 .122312$
Background: All forms of surgical therapy are stressful and injurious. The problems of paralysis, renal dysfunction, and colonic ischemia associated with aortic occlusion are due to acute ischemia-reperfusion injury at the cellular level. Acute-anterior spinal cord ischemia is the most devastating outcome of these iatrogenic-ischemic events. The majority of surgical procedures are performed electively and therefore provide an opportunity to preoperatively condition the patient to minimize these ischemia-related morbidities.

Objectives: We sought to determine whether acute spinal cord injury associated with aortic occlusion can be prevented by induction of the cellular stress response by means of preoperative administration of whole-body hyperthermia or stannous chloride.

Methods: The study consisted of an experimental rabbit model of infrarenal aortic occlusion for 20 minutes at normothermic body temperature.

Results: Control rabbits experienced an 88\% (7/8) incidence of paralysis after spinal cord ischemia induced by 20 minutes of aortic occlusion, whereas animals treated preoperatively with either whole-body hyperthermia (0/9) or stannous chloride (0/4) never became paralyzed $(P<.001$ for control vs treated groups). Ischemic protection of the spinal cord was associated with increased content of stress proteins within tissues of pretreated animals.

Conclusion: Prior induction of the heat shock response in the whole animal will increase the content of stress proteins within the spinal cord and other tissues and result in the prevention of hind-limb paralysis associated with aortic occlusion. We have designated the preoperative induction of the cellular stress response for the prevention of ischemic tissue injury stress conditioning. We suggest that stressconditioning protocols represent the opportunity to practice preventative medicine at the molecular level.

"Cum melius et utilius sit in tempore occurrere quam post causam vulneratam quaerrere remedium." (Prevention is better than cure.)

-Bracton, ${ }^{1}$ circa 1240

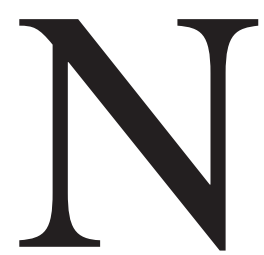

owhere in modern surgical therapy is the damage from ischemiareperfusion events more poignant and devastating than that which complicates successful aortic reconstructive surgery. Acute spinal cord ischemia resulting in clinical neurologic deficits remains a frequent (8\%-10\% incidence) and stubborn problem, resisting solution by physicians and scientists alike. ${ }^{2}$ A recently described metabolic hallmark of ischemic tissue is the enhanced expression of heat shock 
TABLE 1. Summary of current clinical approaches for ischemic protection of the spinal cord during aortic surgery

\begin{tabular}{|c|c|c|}
\hline Preoperative & Intraoperative & Postoperative \\
\hline $\begin{array}{l}\text { Patient } \\
\text { Age } \\
\text { Comorbidities } \\
\text { Tobacco use } \\
\text { Extent of disease-dissection } \\
\text { Patency of ICA } \\
\text { Reoperative surgery }\end{array}$ & $\begin{array}{l}\text { Technical } \\
\text { Ischemia time }<30 \text { min } \\
\text { Clamp and sew } \\
\text { Reattachment of ICA } \\
\text { Shunts } \\
\text { Active vs passive } \\
\text { Open distal anastomosis } \\
\text { Staged crossclamping }\end{array}$ & NA \\
\hline $\begin{array}{l}\text { Pharmacotherapy } \\
\text { Stress conditioning: } \mathrm{SnCl}_{2}{ }^{*}\end{array}$ & $\begin{array}{l}\text { Pharmacotherapy } \\
\text { ROS scavengers } \\
\text { Mannitol } \\
\mathrm{Ca}^{2+} \text { channel blocker } \\
\text { Corticosteroids } \\
\text { Barbiturates } \\
\text { Iron chelators } \\
\text { Allopurinol } \\
\text { Propofol } \\
\text { Naloxone } \\
\text { Papaverine } \\
\text { Lidocaine/"spinoplegia” } \\
\text { Stress conditioning* }\end{array}$ & $\begin{array}{l}\text { Pharmacotherapy } \\
\text { Avoid opiates } \\
\text { Stress conditioning* }\end{array}$ \\
\hline $\begin{array}{l}\text { Biologic } \\
\text { Stress conditioning* } \\
\text { Hyperthermia } \\
\text { Ischemic preconditioning* }\end{array}$ & $\begin{array}{l}\text { Biologic } \\
\text { Hypothermia } \\
\text { Regional } \\
\text { Systemic, } \pm \text { CPB } \\
\text { Perfusion pressure } \\
\text { Systemic BP } \\
\text { CSF pressure } \\
\text { Evoked potentials } \\
\text { WBC-depleted blood transfusion } \\
\text { Stress conditioning* }\end{array}$ & $\begin{array}{l}\text { Biologic } \\
\text { Perfusion pressure } \\
\text { Systemic BP } \\
\text { CSF pressure } \\
\text { WBC adherence } \\
\text { Tissue edema } \\
\text { Stress conditioning* }\end{array}$ \\
\hline
\end{tabular}

$I C A$, Intercostal artery; $S n C l$, stannous chloride; $R O S$, reactive oxygen species; $C P B$, cardiopulmonary bypass; $B P$, blood pressure; $C S F$, cerebral spinal fluid; $W B C$, white blood cell; $N A$, none available.

${ }^{*}$ No clinical trials or protocols and limited preclinical reports.

response or stress genes. ${ }^{3-6}$ This alteration in cellular metabolism is known to occur in all cells when exposed to severe stress and is therefore a predictable phenomenon. This altered metabolic state is transient and characterized by the greatly enhanced synthesis of stress proteins, especially the inducible isoform of the $70-\mathrm{kd}$ heat shock protein (iHSP70). The dominant phenotypic change associated with new heat shock gene expression is the increased resistance of cells and tissues to life-threatening conditions, such as ionizing radiation, reactive oxygen species, and inflammatory cytokines. ${ }^{7}$

Despite the extensive knowledge base within the disciplines of ischemia-reperfusion biochemistry and clinical aortic surgery, very little has been translated into safe, simple, and practical methods to prevent ischemic spinal cord injury in the setting of aortic surgery. Numerous logical approaches have been tested, and in general, all have fallen short of the clinical need. A sampling of the current approaches is listed in Table 1 for review. A paucity of preoperative conditioning protocols is readily apparent within this list. We have sought to develop preoperative conditioning protocols aimed at attenuating ischemiareperfusion injury in common clinical settings by focusing on the preoperative activation of protective mechanisms intrinsic to all cells. We have successfully protected rodent and porcine kidneys and rodent skin flaps from acute ischemia-reperfusion injury. 8,9

This report tests the following hypotheses: (1) stress conditioning of the whole animal by means of preoperative induction of the heat shock response will prevent paralysis caused by acute spinal cord ischemia in a rabbit model of infrarenal aortic occlusion; (2) induction of heat shock gene expression by means of whole-body hyperthermia or by pharmacologic means (stannous chloride) will be equally effective at providing ischemic spinal cord protection; and (3) ischemic protection will be associated with the increased content of stress proteins within tissues taken from pretreated animals. 


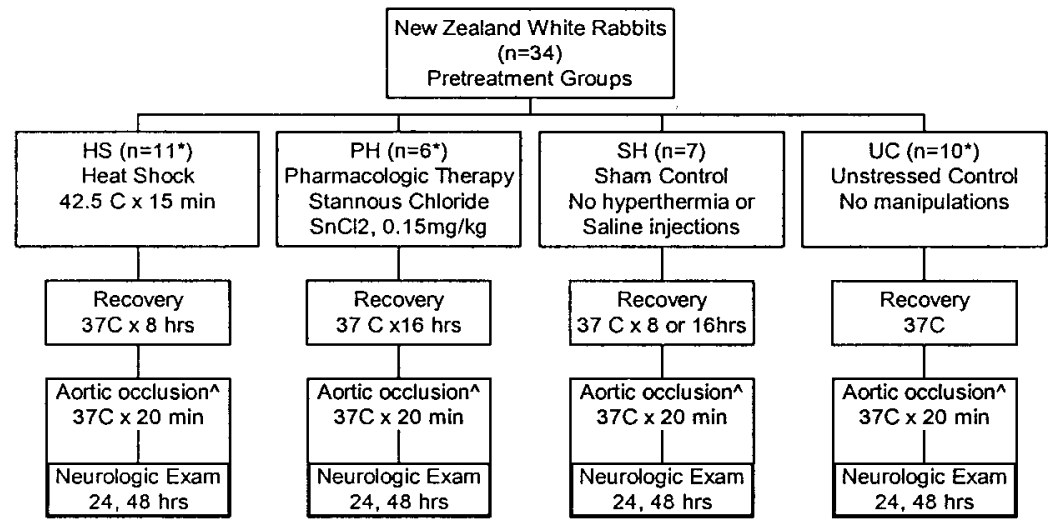

Figure 1. Experimental design. *Two animals from each group were killed for HSP determinations 8 hours after heat shock or 16 hours after stannous chloride administration. ^Skeletal muscle was sampled for determination of iHSP70 content.

\section{Materials and Methods}

All experiments were performed within the guidelines outlined by the "Guide for the Care and Use of Laboratory Animals" published by the Institute of Laboratory Animal Resources, Commission on Life Sciences (National Research Council, 1996), and in compliance with the Animal Care and Use Committee at our institution.

\section{Animals \\ New Zealand White rabbits $(3 \mathrm{~kg}$, female, $\mathrm{n}=34$ ) were divided into 4 groups according to the pretreatment protocol administered. The heat shock (HS, $\mathrm{n}=11$ ) group was pretreated with whole- body hyperthermia $\left(42.5^{\circ} \mathrm{C} \pm 0.3^{\circ} \mathrm{C} \times 15\right.$ minutes $)$, followed by 8 hours of normothermic recovery. The sham $(\mathrm{SH}, \mathrm{n}=7)$ group received identical anesthesia, restraint, and recovery as the HS group, without exposure to hyperthermia. The pharmacologic group $(\mathrm{PH}, \mathrm{n}=6)$ received an injection of stannous chloride $(0.15$ $\mathrm{mg} / \mathrm{kg}$ administered subcutaneously), followed by 16 hours of normothermic recovery. The unstressed control (UC, $\mathrm{n}=10$ ) group received no manipulations. Two animals from the HS and UC groups were killed 8 hours after whole-body hyperthermia to survey tissues for HSP expression (see Figure 1 for outline of experimental design).}

\section{Whole-Body Hyperthermia and Recovery}

The HS group of animals pretreated with whole-body hyperthermia were sedated $(35 \mathrm{mg} / \mathrm{kg}$ ketamine administered intramuscularly and $1 \mathrm{mg} / \mathrm{kg}$ acepromazine maleate [INN: acepromazine] administered intramuscularly), intubated, and mechanically ventilated with room air. No inhalational anesthetic was administered. Each animal received an initial loading dose of physiologic saline $(25 \mathrm{~mL} / \mathrm{kg} 0.9 \% \mathrm{NaCl}$ administered intravenously), followed by a constant intravenous infusion $\left(15 \mathrm{~mL} \cdot \mathrm{kg}^{-1} \cdot \mathrm{h}^{-1}\right)$ during the application of hyperthermia. A Mon-a-Therm rectal temperature sensor (Mallinckrodt Anesthesia Products, St Louis, Mo), electrocardiograph electrodes, and a pulse oximeter were used for continuous monitoring of core body temperature (CBT), cardiac rate, and tissue oxygen saturation, respectively. Each animal was placed in a watertight polyethylene bag and submerged up to the neckline in a water bath pre-equilibrated to $46^{\circ} \mathrm{C}$. CBT was monitored continuously until the desired temperature (ie, $42.5^{\circ} \mathrm{C} \pm 0.3^{\circ} \mathrm{C}$ ) was achieved and then maintained for 15 minutes. The usual time required to achieve the targeted CBT of $42.5^{\circ} \mathrm{C}$ was approximately 60 minutes (Figure 2). After the whole-body hyperthermia pretreatment, each animal was actively cooled by means of topical application of isopropyl alcohol solution to the ears until a basal CBT of $38^{\circ} \mathrm{C} \pm 0.3^{\circ} \mathrm{C}$ was reached. Animals were then returned to their cages at room temperature to recover for 8 hours $\left(38^{\circ} \mathrm{C}\right)$ before aortic surgical manipulation. $\mathrm{SH}$ animals received the same anesthesia, monitoring, and restraint as the HS group, but the temperature of the water bath and CBT were maintained at $38^{\circ} \mathrm{C} \pm$ $0.2^{\circ} \mathrm{C}$.

\section{Pharmacologic Induction}

Animals received stannous chloride $\left(\mathrm{SnCl}_{2} ;\right.$ Sigma-2752, 0.15 $\mathrm{mg} / \mathrm{kg}$ administered subcutaneously) in sterile $0.9 \%$ saline 16 hours before aortic occlusion. No sedation, anesthesia, restraint, intubation, or other means of intervention was administered. Stannous chloride is known to induce the synthesis of heme oxygenase (HO-1), a stress-inducible protein, also known as the 32-kd heat shock protein (HSP32). ${ }^{10-12}$

\section{Aortic Occlusion}

All animals underwent 20 minutes of normothermic aortic occlusion through a midline laparotomy incision after recovery from pretreatment, as described above. All animals were sedated, intubated, and mechanically ventilated, as described above. Inhalational anesthetic was delivered through an Engler Veterinary Anesthesia machine (1.0\%-2.5\% isoflurane, $100 \%$ oxygen; minute ventilation, $0.25 \mathrm{~L} / \mathrm{kg}$ ). Maintenance intravenous fluids (Ringer's lactate solution, $25 \mathrm{~mL} \cdot \mathrm{kg}^{-1} \cdot \mathrm{h}^{-1}$ ) were administered throughout the duration of the operation. Animals were prepped and draped in a sterile manner for midline, left neck, and left groin incisions. Twenty-two-gauge arterial catheters were placed in the left carotid and left femoral arteries for continuous monitoring of mean arterial pressures. The intra-abdominal aorta was occluded with 2 side-byside vascular clamps at a level just distal to the takeoff of the left 
renal artery. Aortic occlusion was defined as a decrease in mean femoral arterial pressure to less than $8 \mathrm{~mm} \mathrm{Hg}$. During the 20 minute period of occlusion, CBT was maintained at $38^{\circ} \mathrm{C} \pm 0.3^{\circ} \mathrm{C}$ with a heating blanket. During the initial 15 minutes of reperfusion, the mean femoral arterial pressure was maintained between 45 and $50 \mathrm{~mm} \mathrm{Hg}$ by means of adjustments in intravenous fluid administration and anesthetic dosage. Arterial cannulas were then removed, and wounds were closed. Animals were allowed free access to food and water during recovery. Postoperative analgesia was provided with buprenorphine $\mathrm{HCl}(0.05 \mathrm{mg} / \mathrm{kg}$ administered subcutaneously).

\section{Neurologic Evaluation}

Neurologic examinations were performed at 4, 6, 8, 12, 24, and 48 hours after reperfusion. Examinations included observation and testing of activity and motor function of the lower extremities. Neurologic scoring was performed according to a 7-point scale adapted from Ushio and colleagues ${ }^{13}$ (normal function $=0$ and paralysis $=6$ ). Animals with a score of greater than 4 after 24 hours of recovery were defined as paraplegic and killed at that time point per guidelines established by our Institutional Animal Care and Use Committee. Animals with scores of 4 or less were followed for 48 hours of recovery and then killed.

\section{Western Blot Analysis}

Representative animals from the HS $(n=2)$ and UC $(n=2)$ groups were killed at 8 hours after hyperthermic pretreatment, and representative animals from the $\mathrm{PH}(\mathrm{n}=2)$ group were killed at 16 hours after stannous chloride administration. A survey of tissues was sampled, including spinal cord, liver, kidney, heart, and skeletal muscle, for determination of iHSP70 and HO-1 content. In addition, representative samples of skeletal muscle were taken from all animals in the functional study at the initiation of aortic surgery and studied for iHSP70 protein content. All samples were snap-frozen in liquid nitrogen and then stored at $-70^{\circ} \mathrm{C}$. Tissues were homogenized, and proteins were separated by means of 1-dimensional polyacrylamide gel electrophoresis and transferred to adsorbent membranes for immunoblotting. Immunoblots were probed for the presence of stress proteins by using a monoclonal antibody (SPA-810 [iHSP70] or OSA-111 [HO-1]; StressGen, Biotechnologies Corp, Vancouver, British Columbia, Canada) as the primary antibody according to established methods. ${ }^{14}$ Bound antibody was detected with a conjugated horseradish peroxidase secondary antibody and visualized with a commercial chemiluminesence system. Data were quantitated by using scanning densitometry (Eagle Eye II Scanner and Eagle Sight software; StrataGene, La Jolla, Calif).

\section{Spinal Cord Histology}

Lower thoracic and lumbar spinal cord samples were retrieved at the time of death and placed in buffered $10 \%$ formalin solution overnight. The fixed tissues were randomly sectioned at 3 equally spaced sites and embedded in paraffin. Multiple cut sections were made for mounting and staining. Standard hemotoxylin and eosin and Sevier silver stains were performed. Random samples representing the UC, HS, and PH groups were processed and photographed at $10 \times$ magnification. Interpretation of ischemic changes was performed in a blinded fashion by Dr Dean Uphoff, Staff

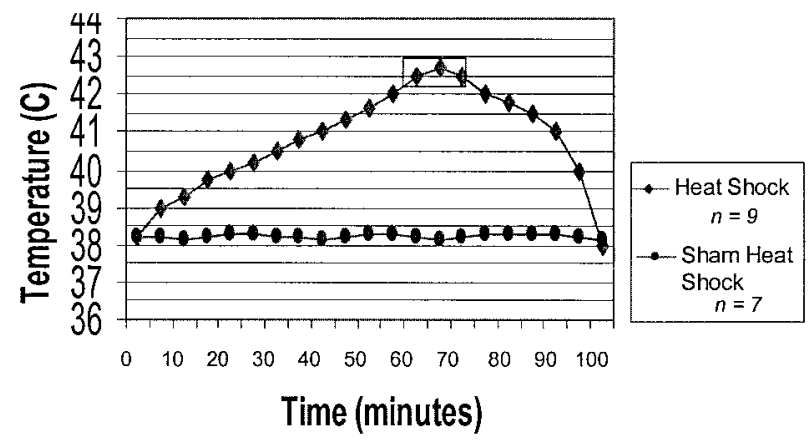

Figure 2. CBT profile of animals $(n=9)$ receiving heat shock pretreatment. Heat shock pretreatment is defined as $42.5^{\circ} \mathrm{C} \pm$ $0.3^{\circ} \mathrm{C}$ for 15 minutes and depicted in the boxed area. All animals $(3 \mathrm{~kg})$ were sedated, mechanically ventilated, and placed in a polyethylene bag to stay dry during immersion into the $46^{\circ} \mathrm{C}$ water bath. Each animal received an initial loading dose of physiologic saline during the application of hyperthermia. CBT was continually monitored with a rectal temperature probe. The boxed area represents exposure to heat shock temperature. Once animals had received 15 minutes at $42.5^{\circ} \mathrm{C}$, they were immediately removed and actively cooled by applying topical isopropyl alcohol to the ears. Animals were then allowed free access to food and water during the following 8 hours of recovery at normal body temperature. Animals appeared active and healthy after this recovery period. SH animals were treated in an identical fashion, except that they were not exposed to hyperthermia, and therefore their $\mathrm{CBT}$ remained at the baseline level $\left(37^{\circ} \mathrm{C}-38^{\circ} \mathrm{C}\right)$.

Pathologist, Hartford Hospital. Samples were assigned one of 3 injury grades (none-mild, moderate, or severe) according to the severity of ischemic changes observed as an average of the 3 sections reviewed for each cord sample.

\section{Statistical Analysis}

Statistical analyses were performed with SPSS for Windows version 8.01 (SPSS, Inc, Chicago, Ill). Summary information is presented as mean $\pm \mathrm{SD}$ or as a percentage. Overall group differences were compared by using analysis of variance, followed by the Tukey procedure for multiple comparisons in the event that the analysis of variance showed statistical significance. Scores for neurologic function were categorized as normal ( score $=0$ ), weak ( score $=1-4)$, or paralysis ( score $=>4$ ) and considered ordinal, with gradations of 1,2, and 3, respectively. Multiple-group differences were analyzed by using the Kruskal-Wallis procedure, followed by the Mann-Whitney $U$ test for group-to-group comparisons. Adjustments for multiple comparisons were made by using the Holm procedure. ${ }^{15}$

\section{Results}

\section{Whole-Body Hyperthermia}

The heating profiles of 9 representative animals are depicted in Figure 2. Heat shock pretreatment is defined as CBT equal to $42.5^{\circ} \mathrm{C} \pm 0.3^{\circ} \mathrm{C}$ for 15 minutes' duration and depicted by the boxed-in area of curve. The time to achieve 
TABLE 2. Hemodynamic and metabolic profiles of experimental groups

\begin{tabular}{|c|c|c|c|c|}
\hline Group (n) & MAP (mm Hg; carotid-femoral) & $\mathrm{pH}$ & $\mathrm{Po}_{2}(\mathrm{~mm} \mathrm{Hg})^{*}$ & $\mathrm{PcO}_{2}(\mathrm{~mm} \mathrm{Hg})$ \\
\hline \multicolumn{5}{|l|}{ HS (9) } \\
\hline Baseline† & $58 \pm 3 / 58 \pm 2$ & $7.39 \pm 0.01$ & $430 \pm 60$ & $51.3 \pm 5.5$ \\
\hline Reperfusion $\ddagger$ & $54 \pm 2 / 47 \pm 1$ & $7.34 \pm 0.04$ & $436 \pm 69$ & $46.7 \pm 7.6$ \\
\hline \multicolumn{5}{|l|}{$\mathrm{PH}(4)$} \\
\hline Baselinet & $58 \pm 2 / 56 \pm 3$ & $7.36 \pm 0.02$ & $440 \pm 66$ & $47.3 \pm 4.4$ \\
\hline Reperfusion $\ddagger$ & $57 \pm 3 / 46 \pm 2$ & $7.33 \pm 0.03$ & $511 \pm 62$ & $44.0 \pm 0.8$ \\
\hline \multicolumn{5}{|l|}{ SH (7) } \\
\hline Baselinet & $58 \pm 1 / 58 \pm 1$ & $7.44 \pm 0.06$ & $436 \pm 64$ & $46.0 \pm 9.3$ \\
\hline Reperfusion $\ddagger$ & $61 \pm 4 / 49 \pm 2$ & $7.38 \pm 0.05$ & $452 \pm 69$ & $48.1 \pm 7.5$ \\
\hline \multicolumn{5}{|l|}{ UC (8) } \\
\hline Baselinet & $57 \pm 1 / 55 \pm 2$ & $7.39 \pm 0.07$ & $404 \pm 13$ & $49.0 \pm 10.7$ \\
\hline Reperfusion $\ddagger$ & $60 \pm 2 / 46 \pm 2$ & $7.34 \pm 0.05$ & $400 \pm 97$ & $51.4 \pm 9.3$ \\
\hline
\end{tabular}

$M A P$, Mean arterial pressure.

*One hundred percent inspired $\mathrm{O}_{2}$.

tTen minutes before aortic occlusion.

$\ddagger$ Two minutes after reperfusion.

TABLE 3. Neurologic function after 20 minutes of warm ischemia $\left(37^{\circ} \mathrm{C}\right)$ and 24 hours of reperfusion

\begin{tabular}{lccc}
\hline Group (n) & Normal, \% (n) & Weak, \% (n) & Paralysis, \% (n) \\
\hline HS (9) & $89(8)^{*}$ & $11(1)$ & $0(0)$ \\
PH (4) & $100(4) \dagger$ & $0(0)$ & $0(0)$ \\
SH (7) & $14(1) \ddagger$ & $72(5)$ & $14(1)$ \\
UC (8) & $0(0)$ & $12(1)$ & $88(7)$ \\
\hline
\end{tabular}

Kruskal-Wallis $\chi^{2}=22.00 ; P=.0003$.

${ }^{*} \mathrm{HS}$ versus $\mathrm{UC}, P=.002 ; \mathrm{HS}$ vs $\mathrm{SH}, P=.024$.

†PH versus $\mathrm{SH}, P=.028 ; \mathrm{PH}$ versus $\mathrm{UC}, P=.016$.

$\ddagger$ SH versus $U C, P=.028$.

the targeted temperature averaged 60 minutes, and total time in the water bath was approximately 75 minutes. Total time during which $\mathrm{CBT}$ was above basal temperature $\left(37^{\circ} \mathrm{C}\right.$ $38^{\circ} \mathrm{C}$ ) approximated 100 minutes. The animals remained hemodynamically stable, with adequate tissue oxygenation throughout the hyperthermia treatment. All animals required active cooling to avoid excessive exposure to hyperthermia, with topical isopropol alcohol solution applied to the ears and evaporated with the aid of a fan. The CBT of $\mathrm{SH}$ animals remained constant at $38.1^{\circ} \mathrm{C} \pm 0.2^{\circ} \mathrm{C}$ (Figure 2).

\section{Hemodynamic Profile}

Intraoperative hemodynamic parameters and arterial blood gas indices 10 minutes before and after aortic occlusion were similar for all groups (Table 2). Aortic occlusion consistently reduced the mean femoral arterial pressure to 0 to $8 \mathrm{~mm} \mathrm{Hg}$ and increased the mean carotid arterial pressure, although the latter was not statistically significant. Mean femoral arterial pressures at the time of reperfusion were consistently between 45 and $50 \mathrm{~mm} \mathrm{Hg}$ for all groups. The recorded CBTs remained at $37^{\circ} \mathrm{C}$ to $38^{\circ} \mathrm{C}$ throughout the surgical procedure and during reperfusion in all animals.

\section{Neurologic Function}

Neurologic scores obtained at 24 hours after reperfusion are summarized in Table 3. Neurologic scores at the 48-hour time point were unchanged from those at the 24-hour time point (data not shown). Normal neurologic function ( score $=0$ ) never returned to the animals in the UC group (normal $=0 / 8)$. The majority of animals in the HS group had normal neurologic function return (normal $=8 / 9$ ), as did the PH animals (normal = 4/4). The SH animals demonstrated an intermediate degree of return of function; however, only one animal demonstrated normal motor function ( $\mathrm{SH}$ group, normal $=1 / 7)$. The difference in neurologic function between the UC group and the $\mathrm{HS}, \mathrm{PH}$, and $\mathrm{SH}$ groups was statistically significant $(P=.002, P=.016$, and $P=.028$, respectively). When compared with the other groups, the $\mathrm{SH}$ group was statistically different from the HS and PH groups $(P=.024$ and $P=.028$, respectively). In addition, the $\mathrm{SH}$ group and the UC group were significantly different $(P=.028)$. Four of the HS animals that were successfully protected from acute spinal cord injury were followed for 2 months, and no neurologic deficits were noted during this extended period of observation.

\section{HSP Content}

Spinal cord from a representative HS animal (Figure 3, A, lane 6) at 8 hours after whole-body hyperthermia demonstrated increased iHSP70 content compared with the trace levels seen in spinal cord from the UC animal (Figure 3, A, lane 10). Densitometric scanning of these protein gels demonstrates an increase in iHSP70 content in all stress-conditioned tissues $(\mathrm{n}=2)$ compared with that in the unstressed control group ( $\mathrm{n}=2$, Figure $3, B$ ). Brief systemic hyperthermia resulted in global increases in iHSP70 content, independent of the tissue type analyzed. Skeletal muscle samples taken at the time of aortic occlusion demonstrated 


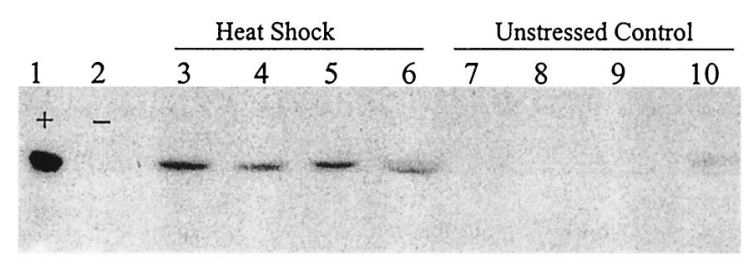

1-rHSP70 positive control

2-rHSC70 negative control

3,7-Liver

4,8-Kidney

5,9-Heart

A

6,10-Spinal cord

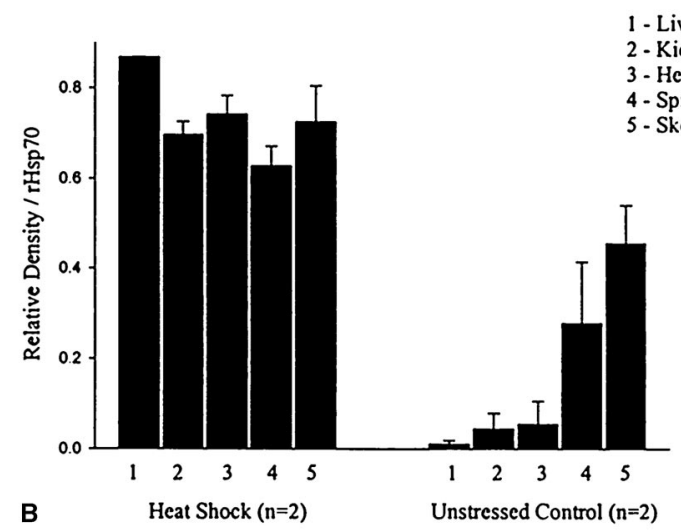

Figure 3. Two additional animals were used to obtain tissue samples at 8 hours after recovery from whole-body hyperthermia $\left(42.5^{\circ} \mathrm{C} \pm 0.3^{\circ} \mathrm{C} \times 15\right.$ minutes) or as unstressed control tissues that came from an animal not receiving systemic hyperthermia. Tissues, including liver, kidney, heart, and spinal cord, were snap-frozen in liquid nitrogen and stored at $-70^{\circ} \mathrm{C}$. Tissues were homogenized, and proteins were separated by means of 1-dimensional polyacrylamide gel electrophoresis and transferred to adsorbent membranes for immunoblotting. Immunoblots were developed by means of indirect immunofluoresence with a monoclonal antibody (SPA-810, StressGen) specific for the inducible isoform of mammalian HSP70 as the primary antibody, according to established methods. ${ }^{14}$ Spinal cord from the HS animal (lane 6) demonstrates elevated iHSP70 content compared with that seen in the spinal cord tissue from the unstressed control animal (lane 10; A). The protein immunoblots were semiquantitated and compared with the Eagle Eye II Scanner and Eagle Sight Software (StrataGene). Densitometric scanning of the protein immunoblot signals demonstrated increased iHSP70 content in all tissues taken from the stress-conditioned animals compared with that seen in the unstressed control group $Z$ (B). Brief systemic hyperthermia resulted in global increases in iHSP70 content, independent of the tissue type analyzed.

elevated iHSP70 in animals from the $\mathrm{SH}, \mathrm{HS}$, and $\mathrm{PH}$ groups compared with the UC animals (Figure 4). Induction of HO-1 was observed in the liver from HS and PH animals and in the kidney from the HS animals but never in any of these same tissues taken from the UC animals (Figure 5).

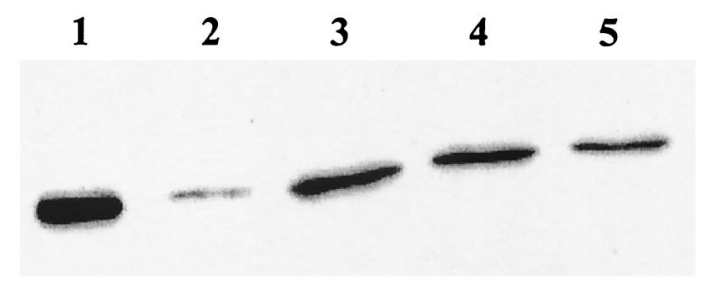
1- rHSP70 positive control
2- UC-Unstressed control
3- Sham heat shock (8hrs)
4- HS-Heat shock ( $8 \mathrm{hr})$
5- PH-Stannous chloride (16hrs)

Figure 4. Skeletal muscle biopsy specimens were taken at the time of aortic occlusion from representative members of each group (SH, HS, and UC) and snap-frozen in liquid nitrogen. Samples were homogenized, and proteins were separated by means of 1-dimensional polyacrylamide gel electrophoresis and transferred to adsorbent membranes for immunoblotting. Immunoblots were developed with a monoclonal antibody (SPA-810, StressGen Biotechnologies Corp) specific for the inducible isoform of mammalian HSP70 as the primary antibody, according to established methods. ${ }^{24}$ The unstressed control animal (lane 2) does not express iHSP70 at the time of aortic occlusion. The HS animal (lane 4) expresses iHSP70, as does the SH animal (lane 3) and the PH animal (lane 5).

The induction of HO-1 was not observed in spinal cord tissue of any animal, independent of group designation. Spleen tissue taken from all animals was always positive for $\mathrm{HO}-1$, which is consistent with the fact that splenic tissue is known to constitutively express HO-1, and is therefore used as a positive control for this work. ${ }^{16}$

\section{Spinal Cord Histopathology}

Representative photomicrographs of the UC (Figure 6, a and d), HS (Figure 6, b and e), and PH (Figure 6, c and f) groups are presented in Figure 6, $A$ (hematoxylin and eosin) and $B$ (silver). The untreated control tissue (Figure 6, a and d) demonstrates severe injury characterized by edema of white matter, disintegration of myelin, and marked axonal swelling. The HS tissue (Figure 6, b and e) shows minimal abnormality, neurons are unremarkable, and there is slight vacuolation of the white matter. No axonal damage is seen. The stannous chloride-pretreated tissue (Figure 6, c and f) shows minimal abnormality, neurons are unremarkable, and there is slight vacuolation of the white matter. No axonal damage is seen. Summary of the blinded scoring of tissues resulted in classifications of severe in the UC group, nonemild in the HS group, and none-mild in the $\mathrm{PH}$ group. No spinal cord necrosis was observed in any specimen in this study, which probably reflects the short recovery time (24-48 hours) relative to the time needed for necrosis to become visible by the stains used here. Occasional areas of 


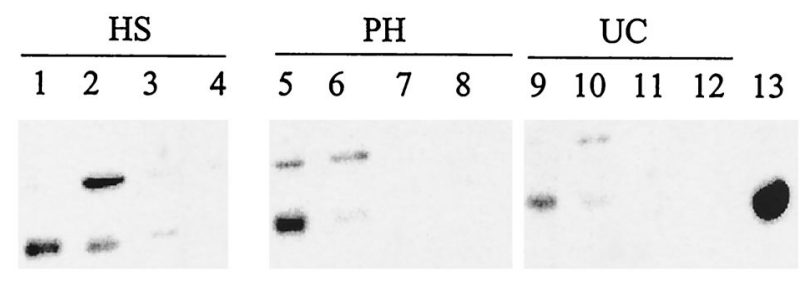

1,5,9-Liver

2,6,10-Kidney

3,7,11-Heart

4,8,12-Spinal cord

13-Spleen- positive control

Figure 5. Two additional animals were used to obtain tissue samples at 8 hours after recovery from whole-body hyperthermia $\left(42.5^{\circ} \mathrm{C} \pm 0.3^{\circ} \mathrm{C} \times 15\right.$ minutes) or at 16 hours after stannous chloride administration or as unstressed control tissues that came from an animal not receiving any form of pretreatment. Tissues, including liver, kidney, heart, and spinal cord, were snap-frozen in liquid nitrogen and stored at $-70^{\circ} \mathrm{C}$. Tissues were homogenized, and proteins were separated by means of 1-dimensional polyacrylamide gel electrophoresis and transferred to adsorbent membranes for immunoblotting. Immunoblots were developed with a monoclonal antibody (OSA111, StressGen Biotechnologies Corp) specific for the inducible isoform of mammalian H0-1 (HSP32) as the primary antibody, according to established methods. ${ }^{14}$ Animals pretreated with HSP had increased content of H0-1 in the liver, kidney, and heart (lanes 1, 2, and 3, respectively) but not in the spinal cord (lane 4) relative to the same tissues from the UC animals (lanes 9-11, respectively). Animals pretreated with stannous chloride had increased content of $\mathrm{HO}-1$ in the liver only (lane 5) relative to the liver from the UC animal (lane 9). Lane 13 represents splenic tissue from a UC animal and serves as a positive control for the anti-HO-1 antibody.

hemorrhage were seen within the UC spinal cord samples but not in the HS, PH, or SH samples (data not shown).

\section{Discussion}

Current medical consensus regarding the problem of spinal cord ischemia in the context of aortic surgery has been succinctly expressed by Cunningham ${ }^{17}$ : "The dilemma of neurologic injury associated with thoracoabdominal aortic reconstructive surgery remains one of the greatest unsolved mysteries for the cardiac surgeon." The gloomy clinical outlook regarding spinal cord ischemia stems from its variable and multifactoral nature. This report demonstrates that preoperative stress conditioning by thermal or pharmacologic means can provide effective ischemic protection of the spinal cord during aortic occlusion in the experimental rabbit model. These results support the concept that induction of the cell stress response can provide tissues with protection from acute ischemia-reperfusion injury, as previously reported by ourselves and others. ${ }^{9}$ The observation that stannous chloride pretreatment can provide tissue-level protection against acute ischemia-reperfusion injury is a new but preliminary finding and is the subject of ongoing work in our laboratory. The in vivo induction of iHSP70 by stannous chloride is a novel observation. Failure to demonstrate $\mathrm{HO}-1$ within the spinal cord tissue remains unexplained.

The observed protection of neurologic form and function from acute ischemia-reperfusion injury is associated with increased content of iHSP70 in the spinal cord, as well as in all other organs tested. The presence of increased iHSP70 in tissues exposed to stressful stimuli is currently interpreted as the dominant metabolic marker, indicating that the cellular stress response has been triggered. The presence of increased content of stress proteins in this model should be cautiously interpreted as being either wholly or in part responsible for the development of cytoprotection. We demonstrate an association, but not a causal relationship, between stress protein content and spinal cord protection from an acute ischemia-reperfusion injury. The metabolic changes associated with the acute cellular stress response are complex and legion. We have referred to the protected state that follows induction of the cell stress response as the protected phenotype, ${ }^{9}$ and it is the topic of ongoing investigations by many. The precise molecular mechanism or mechanisms of this protection have yet to be defined. The HSPs have recently been classified as part of a larger family of proteins designated as molecular chaperones and in this capacity could provide support to proteins and enzymes threatened by acute ischemia. Molecular chaperones work to preserve the structural integrity of cellular proteins and enzymes, especially during stressful destabilizing events like the acute ischemia-reperfusion injury experienced during aortic surgery. ${ }^{18}$

Characteristics of stress-conditioning techniques that favor their use in the setting of complex aortic surgery include the following. First, protection can occur without the need to define the specific mechanisms of injury. Second, global cytoprotection occurs within the stress-conditioned individual. Thus not only does the spinal cord develop ischemic protection, but this should also be true for other tissues of the same individual as well. Third, preoperative stressconditioning techniques can be readily integrated into currently used protocols, such as intraoperative epidural cooling techniques. ${ }^{19}$ Finally, the duration of cytoprotection is expected to last 8 to 24 hours or longer, well into the early postoperative period, when hemodynamic instability and increasing tissue edema continue to pose additional noxious threats to the recovering patient.

We demonstrate the dramatic ability to protect spinal cord function during 24 to 48 hours after aortic occlusion in 


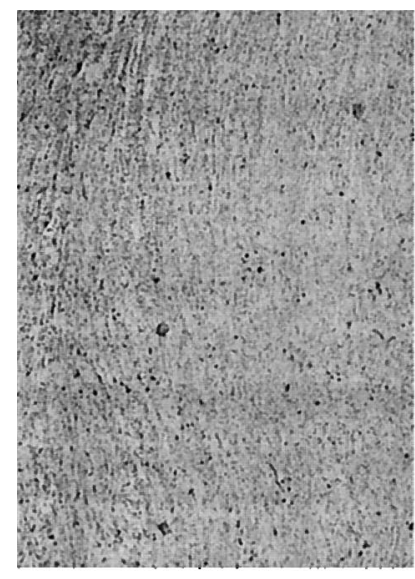

A $\mathbf{a}(\mathbf{U C})$

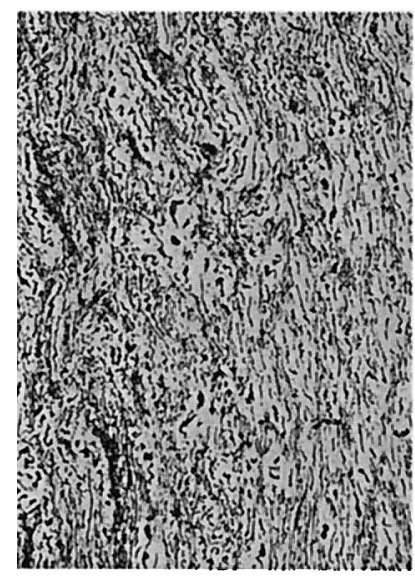

B d (UC)

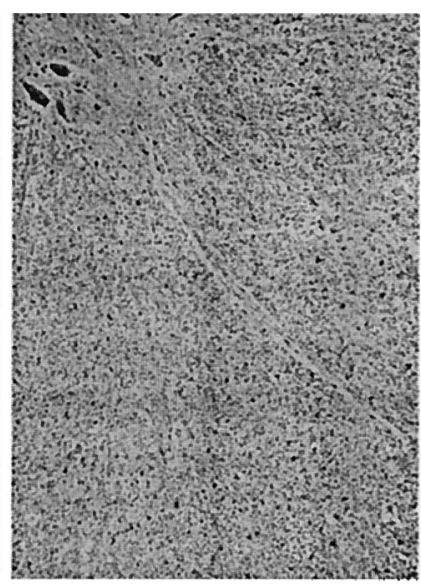

b (HS)

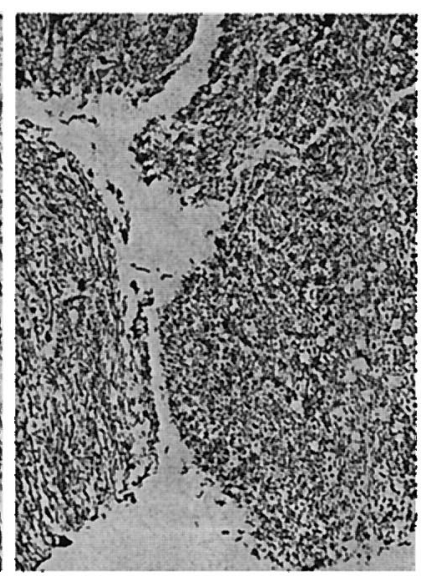

e (HS)

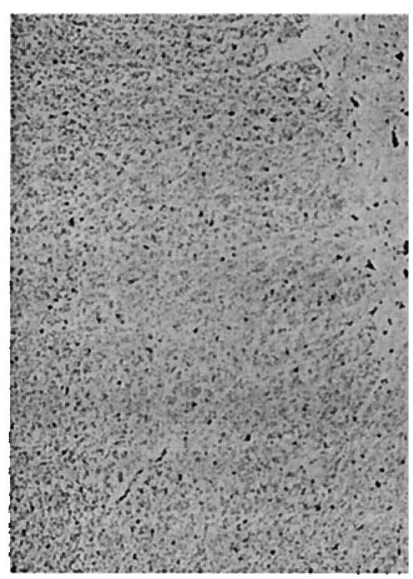

c (PH)

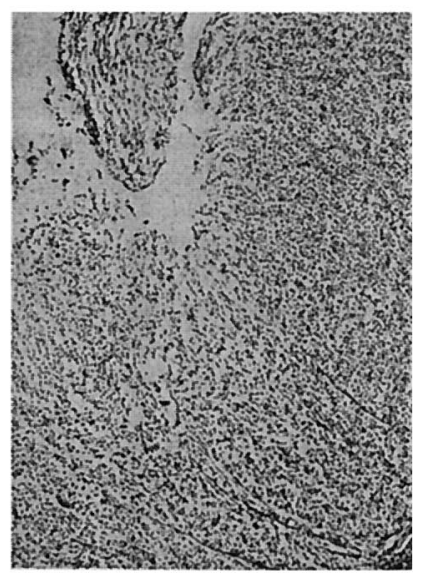

$\mathbf{f}(\mathbf{P H})$

Figure 6. Lower thoracic and lumbar spinal cord samples were retrieved at the time of death and placed in buffered $10 \%$ formalin solution overnight. The fixed tissues were sectioned horizontally at 3 equally spaced sites along the sample and embedded in paraffin. Multiple cut sections were made for mounting and staining. Standard hemotoxylin and eosin (H\&E; A) and Sevier silver (B) stains were performed. Random samples representing the UC $(a$ and $d)$, HS $(b$ and $e)$, and PH $(c$ and $f)$ groups were processed and photographed at $10 \times$ magnification. Interpretation of ischemic changes was performed in a blinded fashion by Dr Dean Uphoff, Staff Pathologist, Hartford Hospital. The UC tissue ( $a$ and $d$ ) demonstrates severe injury characterized by edema of white matter, disintegration of myelin, and marked axonal swelling. The heat HS tissue (b and $e$ ) shows minimal abnormality, neurons are unremarkable, and there is slight vacuolation of the white matter. No axonal damage is seen. The PH tissue ( $c$ and $f$ ) shows minimal abnormality, neurons are unremarkable, and there is slight vacuolation of the white matter. No axonal damage is seen.

the rabbit. The goal of this work was to select a simple and clear end point, paralysis, to serve as an unambiguous outcome. The neurologic scoring system used here is somewhat broad and therefore might have missed subtle differences in neurologic function between or within groups. This scoring system reflects a clinically based tool that is widely reported in the literature. ${ }^{13,20,21}$ Because of the short follow-up time for all animals demonstrating paralysis, it is unclear whether some of the pretreated animals might have experienced paralysis at 48- to 72-hour time points. The literature does support the potential for mild worsening in neurologic function at 48 hours (vs 24 hours) in approximately $10 \%$ of animals. ${ }^{22}$ However, 4 (44\%) of the HS animals that were successfully protected from acute spinal cord injury were followed for 2 months, and no new neurologic deficits were observed during this extended period 
of time, suggesting that the problem of delayed development of paralysis is a minor one for this study. Furthermore, the presence of paralysis at 24 hours is predictive of paralysis at the 48-hour time point, thus making delayed recovery an uncommon event for this model. ${ }^{22}$ All animals demonstrating paralysis were killed within 24 hours for humane reasons, as required by our Institutional Animal Care and Use Committee.

In this report we have included our preliminary work focusing on stannous chloride, a tin salt, as a potentially safe and effective stress-conditioning agent for future clinical use. Additional translational animal studies are currently in progress to better define the safety and efficacy of these metal-based agents. ${ }^{23}$

\section{Conclusions}

First, preoperative stress conditioning in the form of wholebody hyperthermia or stannous chloride administration and recovery can prevent paralysis in a rabbit model of aortic surgery.

Second, ischemic spinal cord protection is associated with the increased content of stress proteins within the spinal cord (iHSP70), as well as in other organs: liver (iHSP70 and HO-1); kidney (iHSP70 and HO-1); heart (iHSP70); and skeletal muscle (iHSP70). These changes in function and stress protein synthesis were associated with preservation of histologic morphology of the spinal cord.

Third, stress conditioning can provide significant cytoprotection where and when cellular injury can be anticipated and planned for, such as in the preoperative setting. Preoperative stress conditioning does not preclude the concomitant use of conventional modalities for spinal cord protection and might have synergistic effects. Stress-conditioning protocols represent preventative medicine practiced at the molecular level.

Finally, stannous chloride pretreatment might provide ischemic spinal cord protection equivalent to that seen after whole-body hyperthermia and represents a clinically appealing methodology by which to achieve preoperative stress conditioning.

Statistical analysis was performed by Mr Jeffery Mather, Hartford Hospital Research Administration. Histolopathology review was provided by Dr Dean Uphoff, Department of Pathology, Hartford Hospital.

\section{References}

1. Bracton, 1240. Oxford Dictionary of English Proverbs. 2nd ed. Oxford: Clarendon Press; 1966. p. 517.
2. Gharagozloo F, Larson J, Dausmann MJ, Neville RF Jr, Gomes MN. Spinal cord protection during surgical procedures on the descending throacic and throacoabdominal aorta: review of current techniques. Chest. 1996;109:799-809.

3. Cairo G, Bardella L, Schiaffonati L, Bernelli-Zazzera A. Synthesis of heat shock proteins in rat liver after ischemia and hyperthermia. Hepatology. 1985;5:357-61.

4. Nowak TS Jr. Synthesis of a stress protein following transient ischemia in the gerbil. J Neurochem. 1985;45:1635-41.

5. Van Why SK, Hildebrandt F, Ardito T, Mann AS, Siegel NJ, Kashgarian M. induction and intracellular localization of HSP-72 after renal ischemia. Am J Physiol. 1992;263:F769-75.

6. Entwistle JW, Graham LJ, Jakoi ER, et al. Myocardial stunning: changes in cardiac gene expression after global ischemia and reperfusion. Surg Forum. 1995;46:209-11.

7. Morimoto RI, Tissieres A, Georgopoulos C. Stress proteins in biology and medicine. Cold Spring Harbor: Cold Spring Harbor Laborataory Press; 1990.

8. Perdrizet GA. Heat shock and tissue protection. New Horizons. 1995; 3:312-20.

9. Perdrizet GA. The heat shock response and organ transplantation. Transplant Rev. 1996;10:78-98.

10. Kappas A, Maines M. Tin: a potent inducer of heme oxygenase in kidney. Science. 1976;192:60-2.

11. Neil T, Abraham N, Levere R, Kappas A. Differential heme oxygenase induction by stannous and stannic ions in the heart. J Cell Biochem. 1995;57:409-14.

12. Keyse SM, Tyrell RM. Heme oxygenase is the major $32-\mathrm{kDa}$ stress proteiin induced in human skin fibroblast by UVA radiation, hydrogen peroxide, and sodium arsenite. Proc Natl Acad Sci U S A. 1989;86: 99-103.

13. Ushio Y, Posner R, Kim JH, Shapiro WR, Posner JB. Treatment of experimental spinal cord compression caused by extradural neoplasms. J Neurosurg. 1977;47:380-90.

14. Towbin H, Staehlin T, Gordon J. Electrophoretic transfer of proteins from polyacrylamide gels to nitrocellulose sheets: procedures and some applications. Proc Natl Acad Sci U S A. 1979;76:4350-4.

15. Holm S. A simple sequentially rejective multiple test procedure. Scand J Stat. 1979;6:65-70.

16. Maines MD. Heme oxygenase: function, multiplicity, regulatory mechanisms, and clinical applications. FASEB J. 1988;2:2557-68.

17. Cunningham JN. Introduction in spinal cord ischemia. Semin Thorac Cardiovasc Surg. 1998;10:3-5.

18. Ellis R, van der Vies S. Molecular chaperones. Ann Rev Biochem. 1991;60:321-47.

19. Cambria RP, Davison JK, Zannetti S, L'Italien G, Brewster DC Gertler JP, et al. Clinical experience with epidural cooling for spinal cord protection during thoracic and thoracoabdominal aneurysm repair. J Vasc Surg. 1997;25:234-43.

20. Agee JM, Flanagan T, Blackbourne LH, Kron IL, Tribble CG. Reducing postischemic paraplegia using conjugated superoxide dismutase. Ann Thorac Surg. 1991;51:911-5.

21. Chen M, Robertson C, Grossman RG, Foltz R, Williams V. Neurological outcome correlated with spinal evoked potentials in a spinal cord ischemia model. J Neurosurg. 1984;60:786-95.

22. Vanicky I, Marsala M, Galik J, Marsala J. Epidural perfusion colling protection against protracted spinal cord ischemia in rabbits. $J$ Neurosurg. 1993;79:736-41.

23. House SD, Guidon PT Jr, Perdrizeet GA, Rewinski M, Kyriakos R, Bockman RS, et al. Effects of heat shock, stannous chloride, and gallium nitrate on the rat inflammatory response. Cell Stress Chaperones. 2001;6:164-71. 